\title{
Size effects of a portable two-phase electronics cooling loop
}

\author{
Tom Saenen ${ }^{\mathrm{a}, *}$, Martine Baelmans ${ }^{\mathrm{a}}$ \\ ${ }^{a}$ Katholieke Universiteit Leuven, Department of Mechanical Engineering, Celestijnenlaan 300A B-3001 Heverlee, \\ Belgium
}

\begin{abstract}
Using a state of the art one dimensional, two-phase, dynamic system model, the size effects of a portable two-phase microchannel electronic cooling system are investigated using different refrigerants (R134a, R236fa, R245fa). Special attention is given to the accumulator size and its limitations for portable applications. An analytical model is developed to investigate the accumulator size effect on the loop and compared to the numerical results obtained from the system model. The influence of various loop parameters and possible improvements is investigated. Finally usable design equations are developed to calculate the needed accumulator size. These equations are further used to compare the performance of the different refrigerants and control techniques with regard to the size effects.
\end{abstract}

Keywords: Two-phase, Portable electronics cooling, Accumulator design, Refrigerant performance

\section{Introduction}

At present there is a notable increase in research towards compact, high heat flux, dedicated cooling solutions for electronic systems. This is due to an ever increasing power density of these electronic components that needs to be dissipated. Conventional cooling using finned heat sinks with air is inadequate to keep up with these increasingly stringent cooling demands.

Liquid cooling using microchannels has been extensively explored and is capable of cooling much higher heat fluxes than conventional cooling solutions. Pioneering work in this field has already been done by Tuckerman and Pease [1] almost three decades ago. Initially experimental work was difficult due to the small size of the microchannels. Because of this, conflicting results and correlations were obtained [2, 3]. However, as measurement techniques and various scale effects were correctly identified, it is now accepted that conventional models can be used to calculate pressure losses and heat transfer in microchannels [4, 5].

Another novel cooling solution that receives a lot of attention in research [6, 7] is the use of flow boiling in microchannels. By using the latent heat of vaporization the heat transfer can be increased by an order of magnitude in comparison with liquid convection. This fact coupled with enhanced temperature stability due to the latent heat makes two-phase cooling a very interesting

"Corresponding author. Tel.: +32-16-322549; fax: +32-16-322985
Email address: tom . saenen@mech . kuleuven . be (Tom Saenen ) 
technique to cool the most demanding applications. Because of its excellent properties large scale flow boiling is widely used in most critical cooling situations (e.g. nuclear reactors).

Although two-phase microchannel cooling holds many promises, some difficulties still prevent this technique from being fully utilized. Such as, unlike single-phase flow, the behavior of the flow is different in microchannels [6- -10$]$. Because of this difference, conventional correlations cannot be used to calculate pressure losses, heat transfer, critical heat flux or flow regimes. Due to the recent intensified research many new correlations have been developed specifically for microchannels [11-14]. With the increase in the number of available experimental data, the range and the quality of the correlations has increased.

While research in the fundamental behavior of two-phase flow in microchannel has already been quite extensive, the general system behavior of a two-phase electronics cooling loop has not received as much attention. Some work has been done on developing cooling cycles for a two-phase cooling system for a computer blade server [15]. Also the stability of a two-phase cooling system has been investigated [16]. Historically detailed system level models of complex two-phase systems and flows have been developed for refrigeration systems and cooling systems of nuclear power plants [17, 18].

Recently a dynamic system model has been developed to simulate a two-phase electronic cooling system [19-21]. The equations of of mass, momentum and energy conservation are numerically solved using finite volume discretization and implicit time integration. Additionally, heat conduction models for the heat sink and heat exchanger are included. Moreover, state-ofthe-art correlations are used to close the numerical equations.

Some differences exist between conventional two-phase cooling systems and small scale microelectronic cooling systems. Indeed, usually strong limits on size and weight of components are imposed, for instance in portable cooling systems, varying from highly mobile (e.g. laptop computer) to moderately mobile (e.g. desktop computer). Most of the conventional applications do not have these strong limitations due to their stationary nature. Furthermore, these size limitations possibly have a large influence on the system behavior. In particular the accumulator can largely influence system behavior.

The focus of the current paper is on the impact of size reduction on a two-phase cooling loop. It is clear that the accumulator is a crucial component in this perspective, as its volume is immediately linked to pressure changes in the system and thus to the boiling temperature in the heat sink. The junction temperature of the electronics is strongly linked with the boiling temperature, as the boiling temperature determines the coolant temperature in the two-phase region of the heat sink. To analyze the size reduction a dynamic system model [19-21] is used. Subsequently an analytical model is developed in section 3 , to characterize these size effects. This model is evaluated against more detailed numerical results in section 4 . This results in design equations for the accumulator comprising the most important system characteristics and requirements. These are derived and discussed in section 5

\section{Numerical system model}

In order to analyze the impact of the accumulator size, a dynamic system model is used. A detailed description of the dynamic system model is beyond the scope of this paper. However, a general overview and relevant properties of the model for the current investigation are summarized in this section. A more in depth description of the system model can be found in the related literature [19-21]. 




Figure 1: Schematic representation of a two-phase cooling system, with (a) the pump, (b) the accumulator, (c) the pre-heater, (d) the microchannel heat sink, (e) the connecting tubing and (f) the heat exchanger with air.

A basic configuration for a two-phase cooling system is presented in Fig. 1 . Such a system typically consists of a pump, a pre-heater, a microchannel heat sink, a heat exchanger with air, an accumulator and connecting tubes. All components are described within the numerical model. Furthermore, the model needs to be able to perform dynamic simulations with single-phase flow, vapor-liquid flow and the transition between these regimes.

The governing equations for flow-area averaged two-phase flow can be formulated in different forms with a varying degree of accuracy. Going from less accurate to more detailed these can be divided into (i) homogeneous models, (ii) diffusion (drift-flux) models and (iii) multifluid models [22]. The present system model is based on the diffusion model. This model is chosen because of the added accuracy in regards to the homogeneous model while not being as computationally costly as the multifluid models. These latter also require numerous interfacial transfer models and correlations [22]. Additionally, the liquid and vapor phases are assumed to be in thermal equilibrium. Viscous heating is neglected as well. The model consists of one mass equation, one mixture momentum equation and one mixture enthalpy equation (neglecting potential energy changes in time). These can be written as [22]:

$$
\begin{gathered}
\frac{\partial \rho}{\partial t}+\frac{\partial G}{\partial s}=0 \\
\frac{\partial G}{\partial t}+\frac{1}{A} \frac{\partial}{\partial s}\left(\frac{A G^{2}}{\rho^{\prime}}\right)+\frac{\partial P}{\partial s}+F+\rho g \sin \theta=0 \\
\frac{\partial \rho h^{\star}}{\partial t}+\frac{1}{A} \frac{\partial A G h}{\partial s}-\frac{\partial P}{\partial t}-\frac{\partial}{\partial s} k \frac{\partial T_{c}}{\partial s}=q \frac{P_{m}}{A}
\end{gathered}
$$

where $s$ is the coordinate in the direction of the flow, $\rho=\alpha \rho_{g}+(1-\alpha) \rho_{l}$ the mixture density, $A$ the cross sectional area of the flow, $G=\alpha \rho_{g} u_{g}+(1-\alpha) \rho_{l} u_{l}$ the mixture mass flux with $u_{g}$ the vapor velocity and $u_{l}$ the liquid velocity. $\rho^{\prime}$ is the apparent momentum density defined by:

$$
\rho^{\prime}=\left(\frac{(1-x)^{2}}{\rho_{l}(1-\alpha)}+\frac{x^{2}}{\rho_{g} \alpha}\right)^{-1}
$$


with $x$ the vapor quality, $\alpha$ the void fraction and $\rho_{l}, \rho_{g}$ the liquid and vapor density respectively at mixture temperature and pressure. Furthermore, $P$ is the pressure, $F$ the frictional and local losses, $g$ the gravitational acceleration and $\theta$ the inclination angle of the flow with respect to the horizontal plane. $h^{\star}$ is the mixture specific enthalpy defined by:

$$
h^{\star}=\frac{\rho_{l}(1-\alpha) h_{l}+\rho_{g} \alpha h_{g}}{\rho}
$$

with $h_{l}, h_{g}$ the saturated liquid and vapor enthalpy. Additionally, $h=x h_{g}+(1-x) h_{l}$ is the mixedcup enthalpy, $k$ the thermal conductivity, $T_{c}$ the mixture temperature, $q$ the heat flux and $P_{m}$ the perimeter of the flow channel.

A first step to numerically solve Eqs. (1) to (3) consists of discretizing the equations based on the finite volume technique. This is performed on a staggered 1 dimensional grid to avoid odd-even pressure-velocity decoupling. Mass and enthalpy are discretized over control volumes $(\mathrm{CVs})$ around the cell centered nodes, whereas the momentum equation is discretized over a staggered grid. The cell centered nodes are positioned so that the discretized pressures coincide with the entrance and exit of the components. This way the individual pressure losses of each component can be deduced without further interpolation. This also means that the entrance and exit of the components coincide with the faces of the momentum control volumes. Special consideration is given to the connection of the accumulator to the flow loop. The connection is made with a perpendicular splitter (T-connection), with the accumulator tubing perpendicular to the flow loop tubing. A momentum CV completely encompasses the splitter and is thus the only momentum CV with 2 velocity components in the entire flow loop. Because both components are perpendicular there exists no momentum transfer towards the accumulator. As a result the accumulator interacts with the loop through its pressure only. Finally the numerical solution of the flow is handled using the SIMPLE algorithm [23].

\subsection{Empirical correlations}

In order to solve the discretized equations, empirical correlations are needed to calculate the void fraction $\alpha$, the frictional pressure losses $f$, local pressure losses $K$ and the heat transfer coefficient $h_{f}$. To calculate the void fraction from the vapor quality, the CISE correlation [24] is used in the macro-scale channels. In the microchannels the correlation of Zhang et al. [25] is used.

To calculate the single-phase pressure losses, fully developed flow is assumed in the larger components of the loop (tubing and heat exchanger). For laminar flow in circular channels the following formula is used : $f=\frac{64}{R e}$, with $R e$ the Reynolds number defined as: $R e=\frac{G D_{h}}{\mu}$, with $\mu$ the dynamic viscosity. For turbulent flow the Colebrook correlation is used [26]. The two-phase pressure losses in the components with macro-scale channels are calculated using the LockhartMartinelli correlation [27].

Because the microchannels can be relatively short, flow development can be an important part of the pressure losses. Therefore, the Yilmaz-Bender correlation [28] is used to calculate the laminar single-phase pressure losses in the microchannels. The saturated two-phase pressure losses in the microchannels are calculated with the Lee and Mudawar correlation [29]. This correlation is a modification of the Lockhart-Martinelli correlation specifically developed for saturated two-phase flow in microchannels.

The main local pressure losses in the system consist of contraction and expansion losses at the in- and outlet of the microchannels. As has been shown in literature [5, 30-32] these losses 
can be a significant portion of the total pressure losses in microchannels. Therefore these cannot be neglected. For single-phase flow the formulas derived by Kays [33] for the contraction and expansion losses are used.

The following expressions for the irreversible pressure losses based on a similar derivation as their single-phase counterparts have shown reasonable agreement with experimental data for microchannels [34]:

$$
\begin{aligned}
& K_{e}=\frac{G^{2}}{2 \rho_{l}}\left(1-\sigma^{2}\right)\left[1+x\left(\frac{\rho_{l}}{\rho_{g}}-1\right)\right] \\
& K_{c}=\frac{G^{2}}{C_{c}^{2}}\left(1-C_{c}\right)\left[-\frac{C_{c}}{\rho^{\prime}}+\frac{1+C_{c}}{2} \frac{\rho_{h}}{\rho^{\prime \prime 2}}\right]
\end{aligned}
$$

where $K_{e}$ and $K_{c}$ are the expansion and contraction loss coefficients (defined referenced to the mass flux in the smallest channel), $\sigma$ is the flow area contraction ratio (always the ratio of the smallest area to the largest area) and $C_{c}$ is the contraction coefficient. $C_{c}$ is calculated using the expression from Geiger [35]. $\rho^{\prime \prime}$ is the apparent energy density which is defined as:

$$
\rho^{\prime \prime 2}=\left(\frac{(1-x)^{3}}{\rho_{l}^{2}(1-\alpha)^{2}}+\frac{x^{3}}{\rho_{g}^{2} \alpha^{2}}\right)^{-1}
$$

The heat sink is divided into four regions to calculate the heat transfer coefficient: the singlephase region, the partial boiling region, the fully developed subcooled boiling region and the saturated two-phase region. The last region is identified by a local thermodynamic vapor quality larger than zero. To separate the partial boiling region from the fully single-phase region, the onset of boiling (ONB) model of Liu et al. [36] is used. This model has been validated using a microchannel test section and shows good agreement with experimental results [36]. The transition from partial boiling to fully developed subcooled boiling is set at the onset of significant void (OSV). The correlation of Saha and Zuber [37] is used to detect this transition.

The laminar heat transfer in the single-phase region is calculated with the Muzychka and Yovanovich correlation [38]. This is a conventional correlation that takes into account flow development and channel geometry. For the turbulent single-phase regime, the Gnielinski correlation is used [39]. The correlation of Bertsch et al. [14] is used to calculate the saturated boiling heat transfer. To ensure a smooth transition between the fully developed subcooled boiling regime and the saturated boiling regime, the correlation of Cooper is used to calculate the fully developed subcooled boiling heat transfer. Finally for the partial boiling regime the interpolation method of Kandlikar [37] is used. This ensures a smooth transition between the single-phase region, partial boiling regime and the fully developed subcooled boiling regime.

In the heat exchanger the primary flow is divided into two regions to calculate the heat transfer coefficient. These consist of a condensation region and a single-phase region. The separation between these regions is set by a local thermodynamic vapor quality equal to zero. In the singlephase region the same correlations as in the single-phase region of the heat sink are used. In the condensation region the correlation of Shah is used [40] to evaluate the heat transfer coefficient. In general, the type of heat exchanger used in portable electronics cooling systems is a crossflow air-liquid heat exchanger. Therefore in the current investigation a multi-louvered finned, crossflow air-liquid heat exchanger is used. For the convective heat transfer coefficient to the air, the correlation by Kim and Bullard is used [41]. 


\subsection{Accumulator modeling}

Because of its importance in a compact cooling system, an accumulator model needs to be included in the system model. To allow phase transition an accumulator of sufficient size is needed. Indeed during such a transition the average density of the coolant will drop, with the mass of the system being constant, this results in an increase of the total volume of the coolant. If the system boundaries are very stiff, such a volume increase is not possible and the phase transition cannot occur. Instead the absolute pressure of the system will increase and the coolant will remain in the liquid phase.

A classic accumulator using inert gas as a compressible volume will become increasingly stiff with decreasing gas volume for the same volumetric change of the system. This stiffness will result in an increased absolute pressure and exit temperature of the heat sink. Furthermore, there will be a decrease in exit vapor quality and boiling length of the heat sink at steady state. With increasingly smaller accumulator size the steady state flow tends to be more single-phase liquid. Because the accumulator size can be severely limited in a portable cooling system, this is an important parameter to investigate.

To model the pressure changes of the accumulator, the inert gas is modeled as an ideal gas undergoing compression by the volume changes. To take into account the cooling of the inert gas (and pressure decrease) a lumped capacitance model of the accumulator is used.

Using the first law of thermodynamics on the inert (ideal) gas and modeling the heat transfer using a lumped capacitance model results in the following equation:

$$
m_{i g} c_{v, i g} \frac{d T_{i g}}{d t}=U A_{i g}\left(T_{e n v}-T_{i g}\right)-P_{i g} \frac{d V_{i g}}{d t}
$$

with $m_{i g}$ the mass, $c_{v, i g}$ the heat capacity at constant volume, $T_{i g}$ the temperature, $P_{i g}$ the pressure and $V_{i g}$ the volume of the inert gas. $U$ is the global heat transfer coefficient between the gas and the environment, $A_{i g}$ is the heat transfer surface area and $T_{e n v}$ is the environmental temperature. Equation (9) can be rewritten using the ideal gas law: $P_{i g} V_{i g}=m_{i g} r_{i g} T_{i g}$, with $r_{i g}$ the specific gas constant, to the following form:

$$
\frac{d P_{i g}}{d t}=\frac{U A_{i g}}{c_{v, i g}}\left(\frac{r_{i g} T_{e n v}}{V_{i g}}-\frac{P_{i g}}{m_{i g}}\right)-\frac{c_{p, i g}}{c_{v, i g}} \frac{P_{i g}}{V_{i g}} \frac{d V_{i g}}{d t}
$$

where $c_{p, i g}$ is the heat capacity at constant pressure.

Equation (10) is numerically integrated in time to obtain the accumulator pressure due to volume changes in the system or subsequent cooling of the accumulator. The heat transfer between the accumulator and the environment is modeled taking into account natural convection on the outside of the accumulator and conduction through the accumulator walls. The numeric integration is performed with the common fourth order Runge-Kutta scheme (RK4). It should be noted that Eq. (10) tends to isothermal compression at longer timescales (steady-state solutions) and to isentropic compression at shorter timescales.

\section{Analytical model}

A simple analytical model, that describes the primary behavior of a two-phase system to the size reduction, is presented in this section. After comparison with the more elaborate dynamic model, it will serve in the final section to deduce design equations. The two parameters that need to be accurately modeled are the boiling temperature and the exit vapor quality of the heat sink. 
The junction temperature of the electronics is strongly linked with the boiling temperature, as the boiling temperature determines the coolant temperature in the two-phase region of the heat sink. Additionally, a decrease in vapor quality means a decrease in two-phase length in the heat sink and thus a decrease in convective heat transfer.

The equation of energy conservation in the heat sink can be written as:

$$
\dot{m}\left(h_{e}-h_{i}\right)=\dot{Q}
$$

with $\dot{m}$ the mass flow rate, $\dot{Q}$ is the heat input, $h_{e}$ and $h_{i}$ the exit and entrance enthalpy respectively. The enthalpy difference between the exit and entrance of the heat sink can be split in a single-phase part and a two-phase part. Assuming a small pressure drop in the single-phase part of the heat sink and assuming that the heat capacity of the liquid is temperature independent this leads to:

$$
\dot{m}\left(c_{p}\left(T_{b}-T_{i}\right)+x_{e} \Delta h\right)=\dot{Q}
$$

where $\Delta h$ is the heat of vaporization, $T_{b}$ is the boiling temperature at inlet pressure, and $x_{e}$ is the exit vapor quality. Using Eq. (12), the exit vapor quality can be calculated from the boiling temperature:

$$
x_{e}=\frac{\dot{Q}}{\dot{m} \Delta h}-\frac{c_{p}}{\Delta h}\left(T_{b}-T_{i}\right)
$$

Alternatively the mass flow rate can be adjusted to keep a constant exit vapor quality. This leads to:

$$
\dot{m}=\frac{\dot{Q}}{x_{e} \Delta h+c_{p}\left(T_{b}-T_{i}\right)}
$$

Finally through inlet temperature control, both the exit vapor quality and mass flow rate can be kept constant for a changing boiling temperature.

From Eq. (13) it is clear that an increase in the boiling temperature results in a decrease in the exit vapor quality. Additionally, from Eq. (14), using mass flow control, mass flow decreases with a boiling temperature increase. Both these effects can lead to a decrease in the overall heat transfer and coupled with a higher coolant temperature, undesirable, high, junction temperatures in the electronics could arise. Therefore the influence on the boiling temperature of various loop parameters needs to be investigated.

The absolute pressure has a strong impact on the boiling temperature through the ClausiusClapeyron relation, which relates the change in boiling temperature to a change in absolute pressure:

$$
\frac{d P}{d T}=\frac{\Delta h}{T \Delta v}
$$

where $\Delta v$ is the difference in specific volume between the vapor and liquid phase. Assuming that the heat of vaporization and the specific volume difference are independent of pressure and temperature (which is a reasonable assumption for relatively small changes in each of them), the following expression can be derived from Eq. (15):

$$
\left(P_{b, 2}-P_{b, 1}\right)=\frac{\Delta h}{\Delta v} \ln \frac{T_{b, 2}}{T_{b, 1}}
$$


Rewriting Eq. (16) leads to:

$$
T_{b, 2}=T_{b, 1} \exp \left(\Delta P \frac{\Delta v}{\Delta h}\right)
$$

As $\Delta h$ and $\Delta v$ are always positive during boiling, the boiling temperature will increase exponentially with a positive pressure change to the system. Alternatively because the vapor density is usually much smaller than the liquid density, $\Delta v$ can be approximated by $v_{g}$. Furthermore, the vapor state function may be approximated by the ideal gas law. This leads to the following form of the Clausius-Clapeyron relation, after integration:

$$
T_{b, 2}=T_{b, 1} \frac{\Delta h}{\Delta h-T_{b, 1} r \ln \left(\frac{\Delta p}{P_{b, 1}}+1\right)}
$$

Finally the boiling temperature rise could also be calculated using an appropriate materials property program or diagram, for example REFPROP [42].

With a system configuration as in Fig. 1 the accumulator will set the lowest pressure in the system. The pump will pressurize the rest of the system to a higher pressure to overcome the various pressure losses. Thus the absolute pressure at the heat sink is set by two different effects, one being the compression in the accumulator and the other being the pressure losses in the system:

$$
\Delta P=\Delta P_{\text {acc }}+\Delta P_{\text {loss }}
$$

with $\Delta P_{a c c}$ the accumulator pressure increase and $\Delta P_{\text {loss }}$ the total pressure losses. Both of pressures differences are influenced by the exit vapor quality of the heat sink and the vapor quality is in turn influenced by the absolute pressure at the heat sink through Eq. (17) (or Eq. (18)), and Eq. (13) when no control is used.

The accumulator pressure increase plays a crucial role in the overall performance of the cooling system. Furthermore, it is strongly interlinked with parameters of the different system components.

Pressure changes in the accumulator originate from volumetric changes in the loop. Because of the small flow volume in the microchannel heat sink, most of the volumetric change of the loop originates from the tubing between the heat sink and the heat exchanger as well as from the heat exchanger. First the volumetric change in the connecting tubing will be investigated, afterwards the volumetric change in the heat exchanger will be elaborated. When a transition from liquid single-phase to two-phase occurs, the tubing between the heat sink and heat exchanger will hold less mass due to the density decrease. However, the total mass in the system is constant and the mass difference in the tubing has to flow to the accumulator. For the connecting tubing, assuming that the vapor quality, vapor density and liquid density are constant throughout the tubing, the mass that flows to the accumulator can be calculated from:

$$
\Delta m_{t}=\alpha\left(\rho_{l}-\rho_{g}\right) V_{t}
$$

where $V_{t}$ is the volume of the tubing between the heat sink and the heat exchanger.

In the heat exchanger the two-phase flow condenses and thus the local void fraction is not a constant. Assuming that the vapor density, liquid density and cross sectional area of the heat exchanger are constant, the mass flow to the accumulator can be calculated from:

$$
\Delta m_{h e}=\left(\rho_{l}-\rho_{g}\right) V_{h e} \frac{1}{L_{h e}} \int_{0}^{L_{h e}} \alpha(s) d s=\left(\rho_{l}-\rho_{g}\right) V_{h e} \alpha_{a v}
$$


Where $V_{h e}$ is the two-phase volume of the heat exchanger, $L_{h e}$ is the two-phase length, $s$ is the flow direction and $\alpha_{a v}$ the average void fraction in the heat exchanger. Note that in order to ensure that the preheater does not have to preheat the flow strongly, the single-phase region of the heat exchanger is preferably small. Therefore the total heat exchanger length and volume can be used in the previous equations as a first approximation for the two-phase length and volume.

However, because of its importance, a more detailed look at the two-phase volume and average void fraction is required. Assuming a constant $\Delta h$ in the heat exchanger, the local vapor quality at a location $L$ in the heat exchanger can be calculated from:

$$
x(L)=\frac{-\int_{0}^{L} Q^{\prime}(s) d s}{\dot{m} \Delta h}+x_{i}
$$

where $Q^{\prime}$ is the heat flow per unit length from the two-phase flow to the air. In general the heat flow per unit length for a heat exchanger can be written as:

$$
Q^{\prime}=U P_{m} \Delta T
$$

where $U$ is the overall heat transfer coefficient, $P_{m}$ is the perimeter associated with $U$ and $\Delta T$ is the temperature difference between the two-phase coolant and the air. For a cross flow heat exchanger with two-phase flow, $\Delta T$ is a constant in the two-phase flow direction. The product $U P$ can be rewritten as $U P=1 / R_{t o t, L}$, where $R_{t o t, L}$ is the total thermal resistance between the two fluids per unit length. The total resistance includes both the convective resistance in the fluids and a conduction resistance through the channel walls. For an air-liquid condenser, the convective resistance on the air-side usually is the dominant thermal resistance. Furthermore, for a cross-flow air-liquid condenser, this resistance can be assumed to be constant in the twophase flow direction. Additionally, the temperature difference is also a constant for such a heat exchanger. Therefore the heat flow per unit length in the heat exchanger can be assumed to be constant in the two-phase flow direction. Equation (22) simplifies to:

$$
x(L)=\frac{-Q^{\prime} L}{\dot{m} \Delta h}+x_{i}
$$

Thus, the vapor quality decreases linearly in the flow direction. Also Eq. (24) can be used to estimate the two-phase length and volume of the heat exchanger. Namely the two-phase length is the length in Eq. (24) that corresponds with a zero vapor quality:

$$
L_{h e}=\frac{x_{i} \dot{m} \Delta h}{Q^{\prime}}
$$

Using an appropriate void fraction correlation and assuming that the vapor quality decreases linearly in the heat exchanger, $\alpha_{a v}$ can be calculated for a given inlet vapor quality. Accordingly, based on the Zivi correlation [43], the void fraction can be written as:

$$
\alpha_{a v}=\frac{\left(\ln \left(\frac{\rho_{g}}{\rho_{l}}\right)^{2 / 3}-x_{i}\right)\left(\frac{\rho_{g}}{\rho_{l}}\right)^{2 / 3}+x_{i}-\left(\frac{\rho_{g}}{\rho_{l}}\right)^{2 / 3} \ln \left(x_{i}-\left(\frac{\rho_{g}}{\rho_{l}}\right)^{2 / 3}\left(x_{i}-1\right)\right)}{\left(\left(\frac{\rho_{g}}{\rho_{l}}\right)^{2 / 3}-1\right)^{2} x_{i}}
$$

In Fig. 2, the average void fraction is plotted for a given inlet vapor quality for three different refrigerants (R134a, R236fa and R245fa) and water at a boiling temperature of $45^{\circ} \mathrm{C}$. 


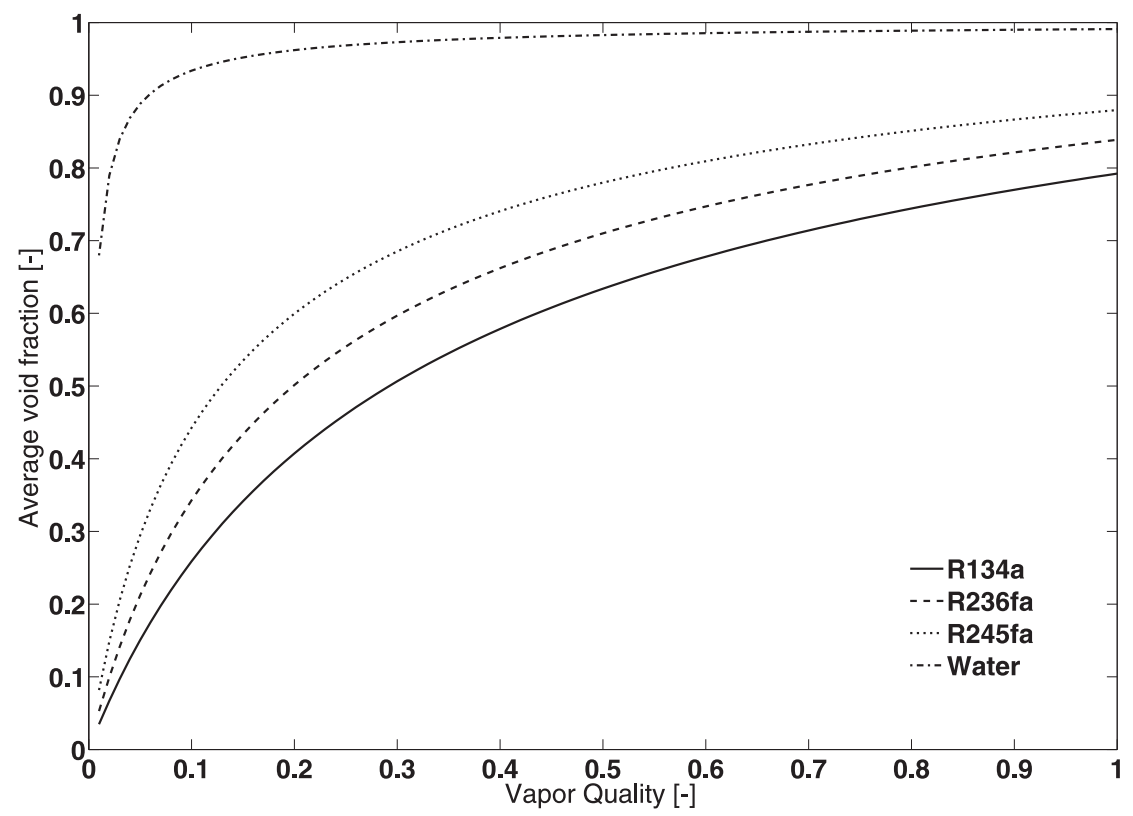

Figure 2: Average void fraction for a given inlet vapor quality for the heat exchanger.

Adding the two mass differences, $\Delta m_{t}$ and $\Delta m_{h e}$, together and assuming incompressible liquid flow, the following liquid volume change in the accumulator results:

$$
\Delta V_{a c c}=\frac{\Delta m_{t}+\Delta m_{h e}}{\rho_{l}}=\frac{\alpha\left(\rho_{l}-\rho_{g}\right) V_{t}+\alpha_{a v}\left(\rho_{l}-\rho_{g}\right) V_{h e}}{\rho_{l}}
$$

For long time scales, isothermal compression can be assumed in the accumulator. This leads to a pressure change given by:

$$
\frac{\Delta P_{a c c}}{P_{a c c}}=\frac{V_{a c c}}{V_{a c c}-\Delta V_{a c c}}-1
$$

where $P_{a c c}$ is the initial pressure in the accumulator, $V_{a c c}$ is the initial volume and $\Delta P_{a c c}$ is the pressure increase from the volume change $\Delta V_{a c c}$. Similarly for short time scales, or a well insulated accumulator, isentropic compression can be assumed. This leads to a pressure change given by:

$$
\frac{\Delta P_{a c c}}{P_{a c c}}=\frac{V_{a c c}^{K}}{\left(V_{a c c}-\Delta V_{a c c}\right)^{K}}-1
$$

with $\kappa$ the ratio of specific heats of the compressible gas.

For the isothermal case, combining Eq. (28) and Eq. (27) leads to:

$$
\Delta P_{a c c}=\frac{P_{a c c}\left(\rho_{l}-\rho_{g}\right)\left(\alpha V_{t}+\alpha_{a v} V_{h e}\right)}{\rho_{l} V_{a c c}-\left(\rho_{l}-\rho_{g}\right)\left(\alpha V_{t}+\alpha_{a v} V_{h e}\right)}
$$


Similarly for the isentropic case, combining Eq. 29) and Eq. (27) gives:

$$
\Delta P_{a c c}=\frac{P_{a c c} V_{a c c}^{k}}{\left(V_{a c c}-\frac{\rho_{l}-\rho_{g}}{\rho_{l}}\left(\alpha V_{t}+\alpha_{a v} V_{h e}\right)\right)^{k}}-P_{a c c}
$$

From Eq. (30) and (31) one can see that an increase in void fraction, $\alpha$ or $\alpha_{a v}$, tubing volume $V_{t}$, two-phase heat exchanger volume $V_{h e}$ or initial pressure $P_{a c c}$ will result in an increased pressure change. Additionally, a decrease in accumulator volume $V_{a c c}$ will also result in an increased pressure change. Finally the isentropic pressure change will be higher than the isothermal pressure change.

Neglecting the influence of the frictional pressure losses, Eq. (30) or Eq. 31), together with Eq. (17) or Eq. (18) and Eq. (12), Eq. (13) or Eq. (14) and an appropriate void fraction correlation, can be used to iteratively calculate the exit vapor quality and the boiling temperature. The results from this simplified model will be compared to the numerical results from the system model in the next section.

\section{Results and discussion}

In this section results from the numerical system model are discussed and compared to the analytical model of the previous section. Additionally, the influence of various loop parameters on the size effects are discussed. Finally, using the analytical model the design of the accumulator in regard to size effects is elaborated.

\subsection{Test case}

The values for the test case are chosen to represent a typical desktop application with a relatively high heat input.

The microchannel heat sink is modeled as a $12.1 \mathrm{~mm}$ wide, $12 \mathrm{~mm}$ long and $750 \mu \mathrm{m}$ thick silicon plate with 60 etched microchannels of $500 \mu \mathrm{m}$ height and $100 \mu \mathrm{m}$ width. The wall thickness of the channel walls is $100 \mu \mathrm{m}$. Surface roughness is neglected in both microchannels and tubing. A constant heat input of $200 \mathrm{~W}$ is used as heat input to the heat sink.

Three different types of refrigerants are used namely R134a, R236fa and R245fa. The tubing in the loop and the pump has an internal diameter of $4 \mathrm{~mm}$. The pump is set to a flow speed that gives an exit vapor quality of $x_{e}=0.3$, assuming that boiling starts at the inlet of the heat sink. This typically results in a flow speed of $0.3 \mathrm{~m} / \mathrm{s}$ for the refrigerants considered, effectively delivering a mass flow rate of $0.0038 \mathrm{~kg} / \mathrm{s}$ for R245fa, $0.005087 \mathrm{~kg} / \mathrm{s}$ for R236fa and 0.004336 $\mathrm{ks} / \mathrm{s}$ for R134a. The accumulator is pressurized to 2.9446 bar for R245fa, 5.1566 bar for R236fa and $11.778 \mathrm{bar}$ for R134a. This results in boiling temperatures of $T_{b}=318 \mathrm{~K}$, or $T_{b}=45^{\circ} \mathrm{C}$. These boiling temperatures (and thus accumulator pressures) have been chosen to be somewhat realistic as the heat exchanger needs to be able to effectively transfer all the heat to the environment at this temperature. Furthermore, the inlet temperatures are initially set at $T_{i}=T_{b}-3 \mathrm{~K}$ or $3 \mathrm{~K}$ subcooling by the preheater. This guarantees plenty of boiling in the microchannels with a well sized accumulator.

The heat exchanger is modeled as a dual pass cross-flow louvered fin air liquid heat exchanger, with 6 flow channels of $20 \mathrm{~mm}$ height and a total flow length of $0.24 \mathrm{~m}$. Additionally, the fin pitch is $1.5 \mathrm{~mm}$, the fin thickness is $0.1 \mathrm{~mm}$, the fin height is the same as the channel spacing, i.e. $10 \mathrm{~mm}$, and the fin depth is the same as the channel height or the air flow depth, i.e. $20 \mathrm{~mm}$. The louver pitch is $2.5 \mathrm{~mm}$, louver length is $8 \mathrm{~mm}$ and the louver angle is $25^{\circ}$. 
Table 1: Simulation parameters

\begin{tabular}{ccccccc}
\hline$W(\mathrm{~mm})$ & $L(\mathrm{~mm})$ & $t_{h}(\mu \mathrm{m})$ & $n(-)$ & $h_{c h}(\mu m)$ & $w_{c h}(\mu m)$ & $w_{w}(\mu m)$ \\
\hline 12.1 & 12 & 750 & 60 & 500 & 100 & 100 \\
\hline$Q(W)$ & $d_{t}(\mathrm{~mm})$ & $L_{h p}(\mathrm{~m})$ & $L_{a c c}(\mathrm{~mm})$ & $L_{h e}(\mathrm{~m})$ & $n_{h e}(-)$ & $h_{h e}(\mathrm{~mm})$ \\
\hline 200 & 4 & 0.1 & 25 & 0.24 & 6 & 20 \\
\hline$F i_{h}(\mathrm{~mm})$ & $F i_{p}(\mathrm{~mm})$ & $F i_{t}(\mathrm{~mm})$ & $F i_{d}(\mathrm{~mm})$ & $\mathrm{Lo}_{p}(\mathrm{~mm})$ & $\mathrm{Lo}_{l}(\mathrm{~mm})$ & $\mathrm{Lo}_{\alpha}\left(^{\circ}\right)$ \\
\hline 10 & 1.5 & 0.1 & 20 & 2.5 & 8 & 25
\end{tabular}

The connecting tubing between the pump and heat sink is $0.1 \mathrm{~m}$ long and the tubing length between the heat exchanger and the pump is also $0.1 \mathrm{~m}$. The connection to the accumulator is made halfway between the heat exchanger and the pump. The tubing to the accumulator itself is $25 \mathrm{~mm}$. The previous dimensions are kept constant for all simulations. However, the diameter and length of the tubing between the heat sink and heat exchanger, the width of the flow channels in the heat exchanger, the heat exchanger fan speed and the compressible volume in the accumulator will be varied. These are nominally set at: connecting tubing diameter and length of $4 \mathrm{~mm}$ and $20 \mathrm{~cm}$, heat exchanger flow channel width of $1 \mathrm{~mm}$ and air flow speed of 1 $\mathrm{m} / \mathrm{s}$. The various simulation parameters are summarized in Table 1

For the numerical simulations convergence criteria are set to $10^{-8}$ for the normalized hydraulic and energy residuals. The normalization of these residuals is done using the residuals of the second iteration. The flow loop simulation is initialized at a constant pressure, equal to the accumulator pressure, a constant temperature (equal to the boiling temperature minus $3 \mathrm{~K}$ ) and an arbitrary guessed flow speed. A steady state solution of the loop is obtained when subsequent changes in the exit vapor quality of the transient solution are smaller than $10^{-4}$. For the isentropic size effects the solutions are obtained similarly but with the heat transfer from the accumulator to the environment turned off. This allows the flow to reach a steady state solution while simulating a well insulated, isentropic (air based) accumulator with a $\kappa$ of 1.4.

\subsection{Isothermal and isentropic size effects}

In this section the results of the simulations are discussed. The effect of the accumulator size, the influence of smaller tubing between heat sink and heat exchanger, smaller flow channels in the heat exchanger, changes in the fan speed and the influence of the coolant are all investigated.

\section{Effect of Accumulator Size}

In Fig. 3 the boiling temperature of the heat sink is plotted in function of the compressible accumulator volume for isothermal and isentropic volume changes, using no mass flow or temperature control for R245fa. The accumulator size is varied from $1 \mathrm{~m}^{3}$ to $2 \times 10^{-6} \mathrm{~m}^{3}$. Apart from the results of the numerical model, the boiling temperature is also calculated using the analytic models from the previous section. The various curves for the analytical models are calculated using different equations for the boiling temperature, i.e. Eq. (17), Eq. (18) or a material properties program. 


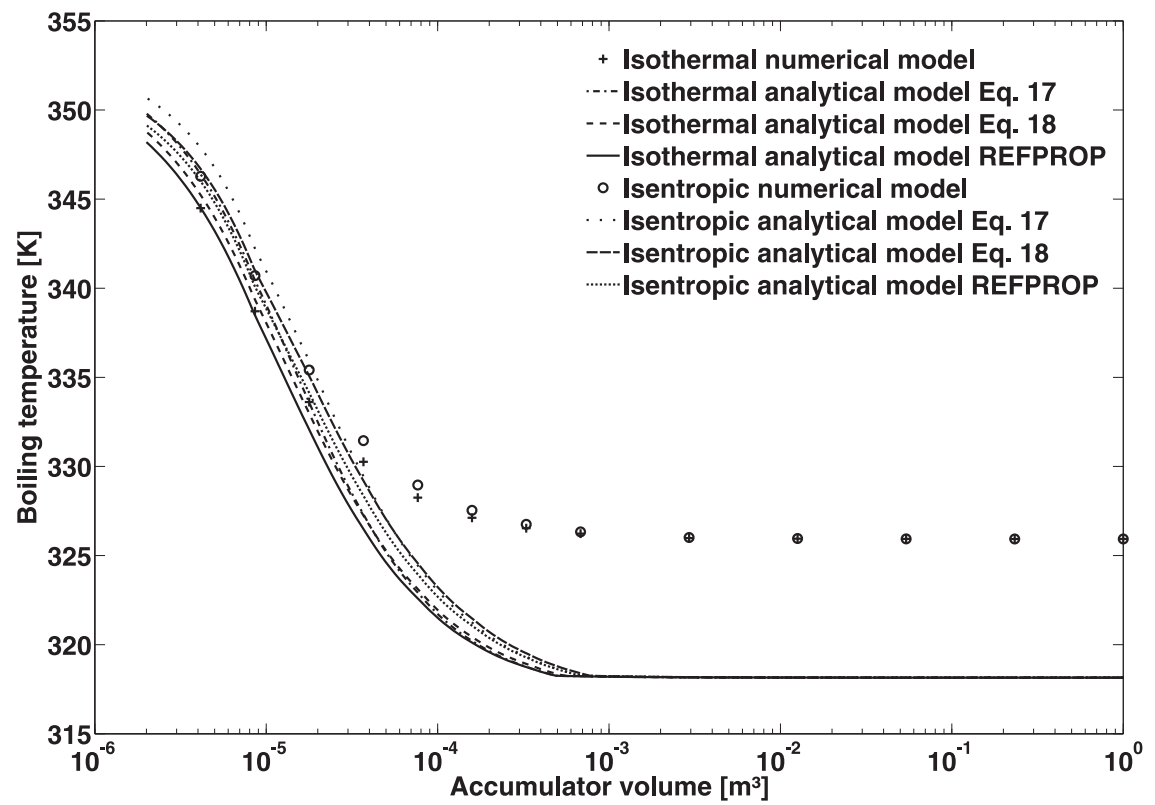

Figure 3: Boiling temperature of the heat sink in function of the compressible accumulator volume, for isothermal and isentropic size effects.

From the results it is clear that the accumulator can have a large effect on the boiling temperatures at smaller volumes. For this particular case, an accumulator volume of $10^{-3}$ will start to have an effect on the exit vapor quality.

As can be seen from the figure, all analytic models perform quite well at smaller accumulator volumes. At higher accumulator volumes the analytic models diverge from the numerical results because these models do not take into account the pressure losses in the system. Indeed, these pressure losses will increase the boiling temperature somewhat at higher accumulator volumes. As the focus of the current paper is on the smaller accumulator volumes, the analytic models can be used for interpretation of the size effects. Furthermore, it can be seen that the more accurate the coolant properties are taken into account the more accurate the prediction is.

In Fig.4t the effect of the compressible accumulator volume on the exit vapor quality is shown for isothermal and isentropic volume changes, using no mass flow or temperature control for R245fa. From the results it is clear that the accumulator can have a large effect on the exit vapor quality at smaller volume ratios. As is the case with the boiling temperature, an accumulator volume of $10^{-3}$ will start to have an effect on the exit vapor quality. Again the isentropic size effects are somewhat stronger, resulting in a lower exit vapor quality, than the isothermal size effects.

It can be concluded, that the simplified models perform quite well in calculating the exit vapor quality for small accumulator volumes.

In Fig. 5 the boiling temperature of the heat sink is plotted in function of the compressible 


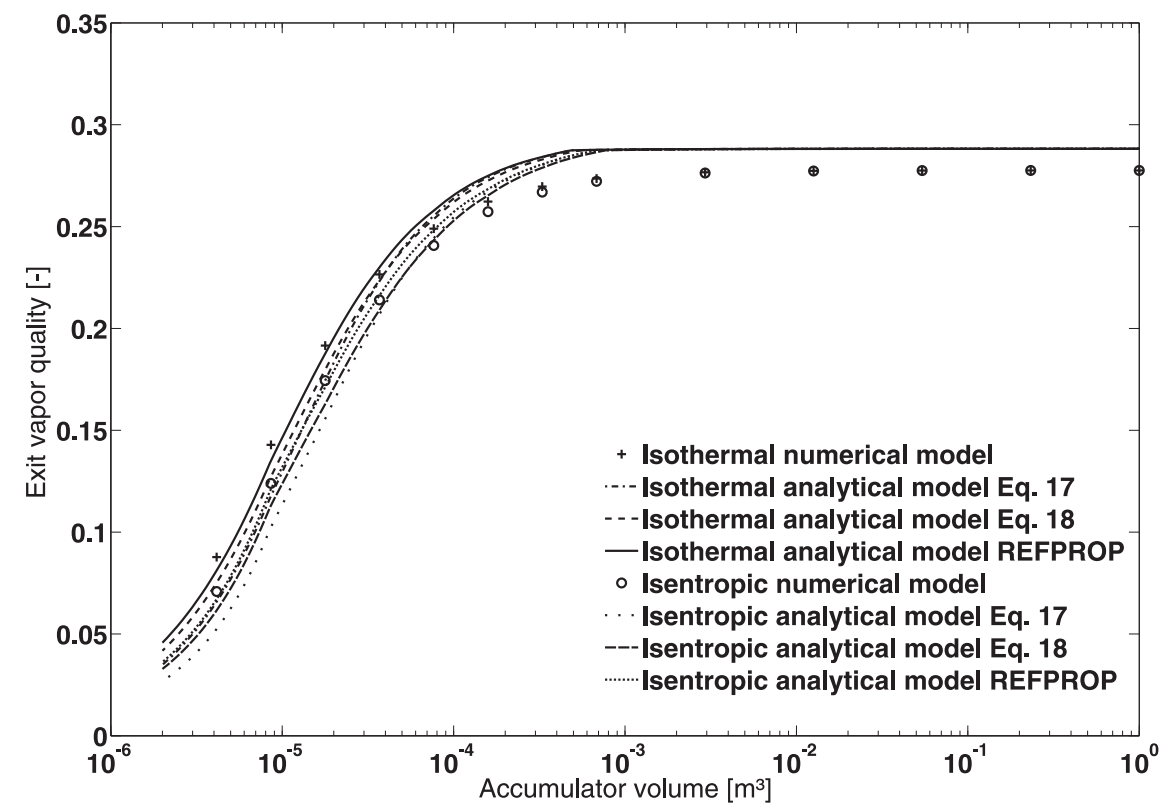

Figure 4: Exit vapor quality of the heat sink in function of the compressible accumulator volume, for isothermal and isentropic size effects.

accumulator volume for isothermal volume changes, for different control techniques for R245fa. As a reference case, the situation without control, meaning a constant mass flow rate and inlet temperature, is examined. This means using Eq. (13) to calculate the exit vapor quality. The second control technique involves modifying the mass flow rate to keep a constant exit vapor. This ensures always plenty of two-phase flow in the heat sink, regardless of the boiling temperature. This mass flow rate can be calculated form Eq. (14). For the results plotted in Fig. 5 the exit vapor quality is set to 0.3 , this ensures plenty of boiling while still providing a safety factor for dry-out [15]. For the final control technique the heat sink inlet temperature is controlled to always have the same temperature difference between the inlet temperature and the boiling temperature. For a constant heat input this results in a constant exit vapor quality and mass flow.

From Fig. 5 it can be seen that the inlet temperature control has the largest size effects, followed by the mass flow control and finally using no control. The reason for this is that the two control techniques keep the exit vapor quality constant and thus the void fraction in the tubing and heat exchanger is also constant. In the case of no control, the vapor quality and hence the void fraction goes to zero at lower accumulator volumes. Finally the difference between mass flow control and temperature control arises from the effect on the heat exchanger. Looking at Eq. (25), the two-phase volume changes with exit vapor quality, mass flow and the heat flow per length in the heat exchanger. The heat flow per length can be calculated from Eq. (23). Because the overall thermal resistance between the coolant and the air is dominated by the air-side, changes in the mass flow or exit vapor quality will only affect the heat transfer at very small mass flow 


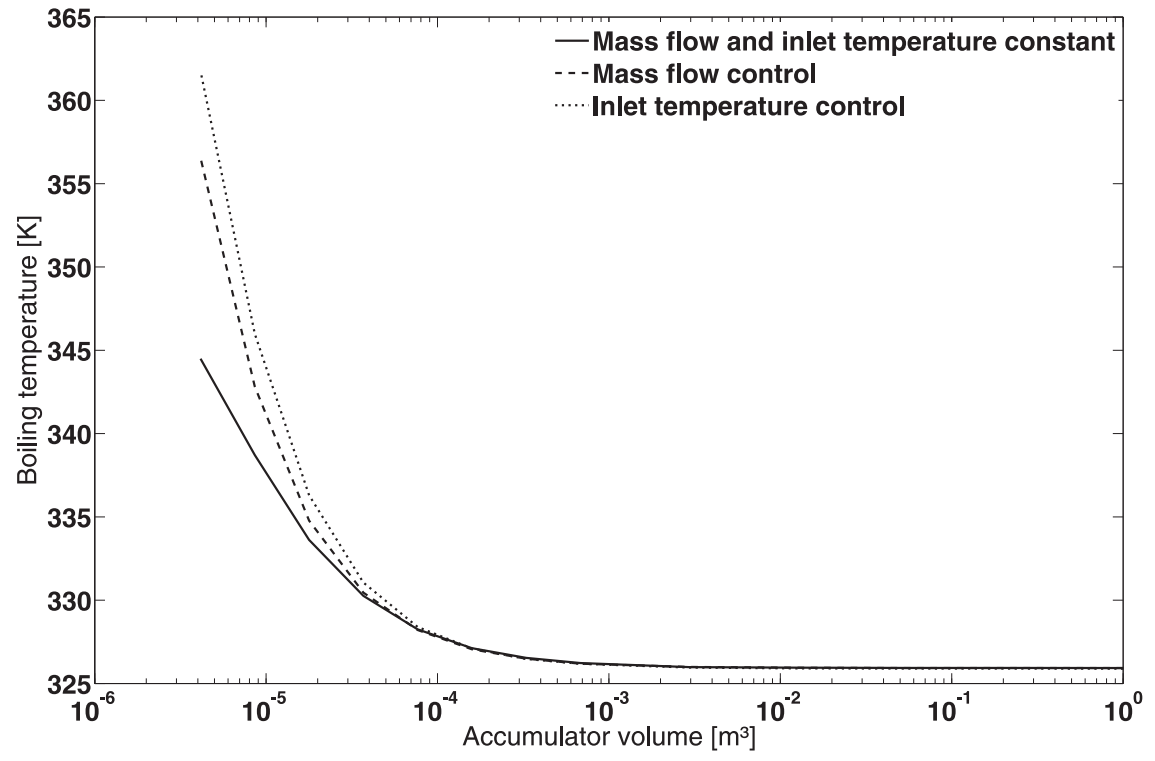

Figure 5: Results from the numerical model for different control techniques.

rates and vapor qualities. Therefore, the $U P_{m}$ factor in Eq. (23) can be considered to be constant. However, the temperature difference will increase with an increase in boiling temperature. From this it is clear that the heat flow per length increases with an increase in boiling temperature. This effect is equal for the mass flow control and temperature control. Because the mass flow and exit vapor quality is constant for the temperature control, the two-phase volume will decrease slightly by the increase in boiling temperature. However, for the mass flow control, the two-phase volume in the heat exchanger will decrease even more because of the mass flow decrease at increasing boiling temperature. This mass flow decrease originates from the control mechanism. Eq. 25] shows that a decrease in mass flow results in a decrease in two-phase length. Because of the smaller two-phase volume in the heat exchanger, the size effects of mass flow control will be lower than with temperature control.

\section{Smaller Tubing Between Heat Sink and Heat Exchanger}

It is clear from the previous section, Eq. (30) and Eq. (31), that the minimal affordable accumulator size is strongly linked with the connecting tubing and heat exchanger volume ( $V_{t}$ and $V_{h e}$ respectively). Therefore, in order to minimize the accumulator size without affecting the pressure changes (and thus changes in the boiling temperature), smaller connecting tubing is necessary.

This is confirmed in Fig. 6 which shows boiling temperature in function of the accumulator compressible volume, with isothermal size effects, no control and different tubing lengths for $\mathrm{R} 245 \mathrm{fa}$. The length of the tubing is varied from $20 \mathrm{~cm}$ to $5 \mathrm{~cm}$ while the diameter is kept constant at $4 \mathrm{~mm}$. As can be seen from the figure, a smaller accumulator can be used without having detrimental effects on the boiling temperature. In addition, the effect is further supported by the fact that a decrease in length will decrease the pressure losses in the system as well as the 


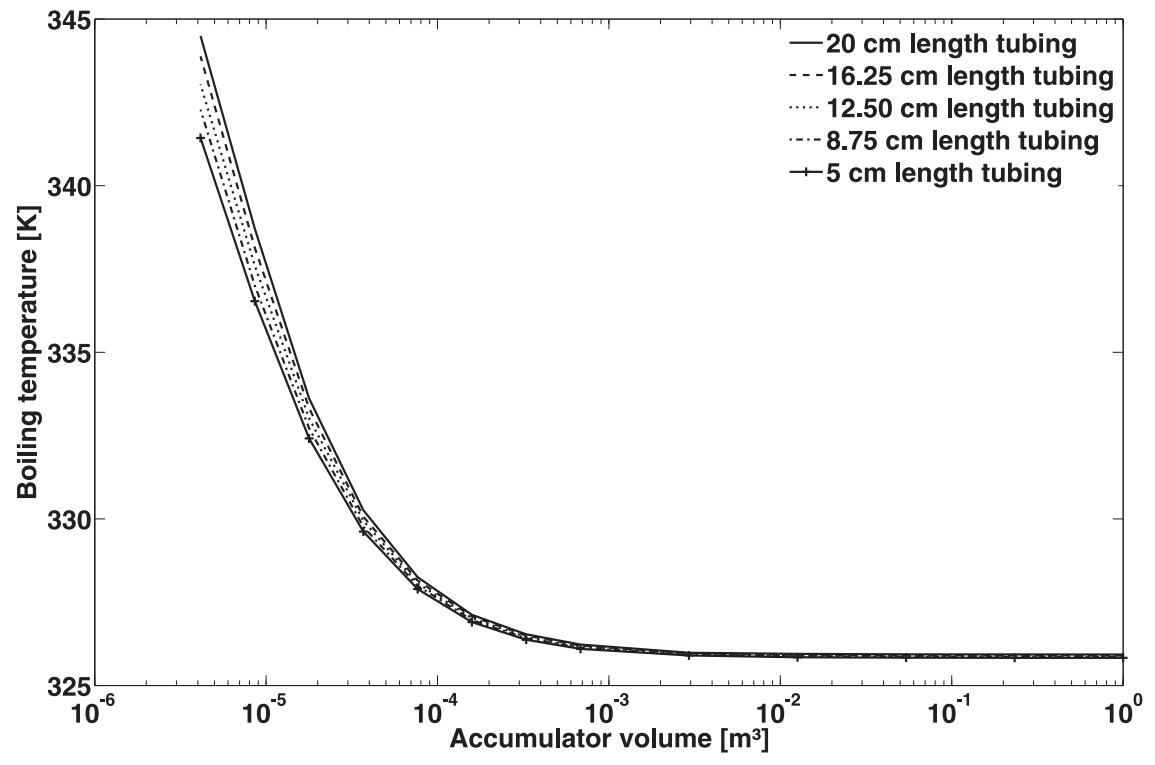

Figure 6: Results from the numerical model for different tubing lengths.

boiling temperature at higher accumulator volumes. Although since the pressure losses in the tubing are relatively small, the latter effect is practically not noticeable in Fig. 6

In Fig. 7 the boiling temperature is plotted in function of the accumulator compressible volume, with isothermal size effects, no control and different tubing diameters for R245fa. The diameter of the tubing is varied from $4 \mathrm{~mm}$ to $2 \mathrm{~mm}$. The length is kept constant at $20 \mathrm{~cm}$. From Fig. 7 there is clear a detrimental effect of a diameter decrease at higher accumulator volumes. This is because a smaller diameter will lead to larger pressure losses, which in turn will lead to higher boiling temperatures. However, at smaller accumulator volumes, the opposite is true. There the pressure change due to the accumulator will become dominant. In addition a diameter decrease will result in a volume decrease of the tubing. Thus, the smaller diameter tubing will have a lower boiling temperature. Therefore, the size effects of different diameters intersect with each other at certain accumulator volumes

\section{Smaller Tubing of the Heat Exchanger and Changing Fan Speed}

Another way to decrease the accumulator size, is by minimizing the two-phase volume in the heat exchanger. This can be done, either by decreasing the flow volume without lowering the overall heat transfer or by increasing the overall heat transfer at the same flow volume. The former can be done by decreasing the flow channel width, as this will decrease the flow volume without strongly affecting the air side heat transfer, which is the restrictive side of the heat transfer. The latter can be done by increasing the air speed at the air side.

Figure 8 shows boiling temperature in function of the accumulator compressible volume, with isothermal size effects, no control and for different heat exchanger flow channel widths for R245fa. The width of the flow channels is varied from $4 \mathrm{~mm}$ to $1 \mathrm{~mm}$ while the other heat 


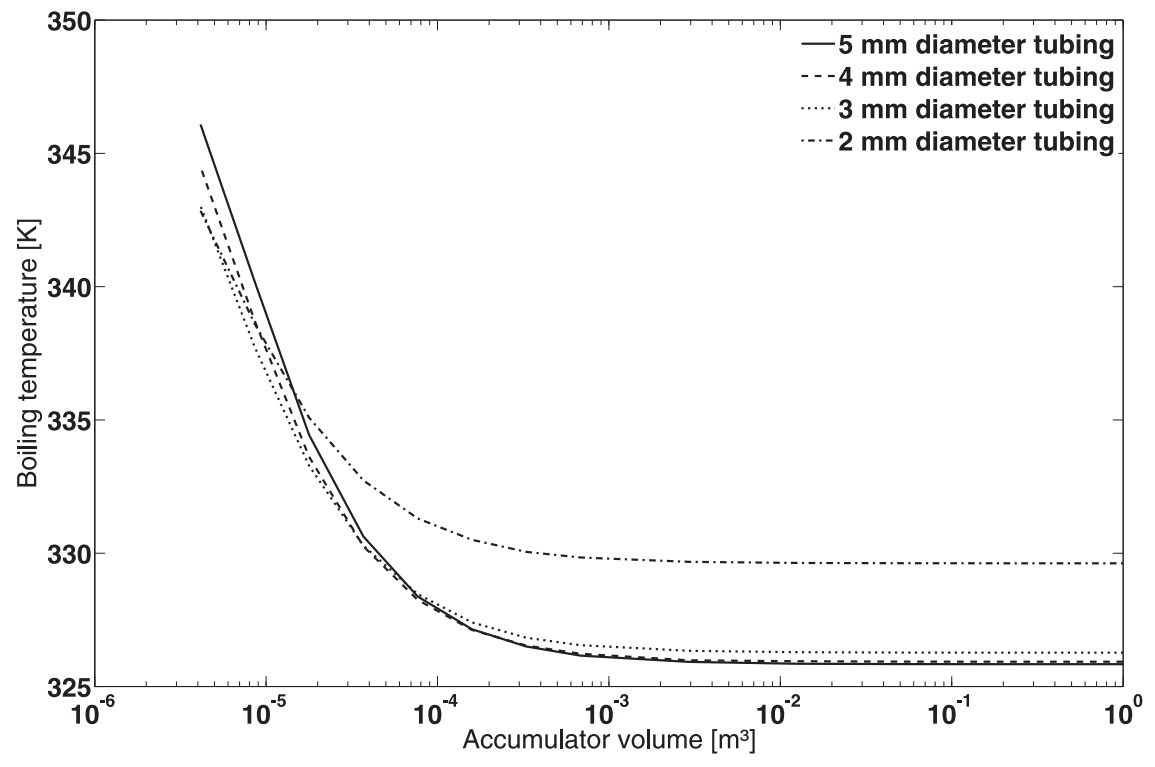

Figure 7: Results from the numerical model for different tubing diameters.

exchanger dimensions are kept constant. As can be seen from the figure, lowering the flow channel width, improves the boiling temperature for the same accumulator size.

Figure 9 shows boiling temperature in function of the accumulator compressible volume, with isothermal size effects, no control and for different heat exchanger air speeds for R245fa. The air speed is varied from $3 \mathrm{~m} / \mathrm{s}$ to $0.5 \mathrm{~m} / \mathrm{s}$ while the other heat exchanger dimensions are kept constant. Increasing the air speed improves the boiling temperature for the same accumulator size. This is due to a decrease in two-phase volume in the heat exchanger, which results in smaller size effects (according to Eq. (30)).

\section{Effect of Coolant}

In this section the effects of different refrigerants on the cooling system performance are given, using no control. Results are obtained for R245fa, R236fa and R134a. Using the settings of the test case, the resulting exit vapor quality of the three different refrigerants are approximately the same (R245fa: 0.2776, R236fa: 0.2747, R134a: 0.2753). This allows for a representative comparison of the different coolants.

In Fig. 10 the isothermal and isentropic results for different coolants are shown. At higher accumulator volumes R245fa shows the highest boiling temperature, followed by R236fa and finally R134a. Again the boiling temperature at higher accumulator volumes is set by the pressure losses in the system. Therefore, the pressure losses using R245fa are the highest, followed by R236fa and R134a. At lower accumulator volumes, where the accumulator effects are dominant, the same order of boiling temperature holds. Additionally, the different coolants start to be influenced by the accumulator size at roughly the same accumulator volume. This is because the tubing and heat exchanger volume is a dominant parameter in the accumulator pressure changes, 


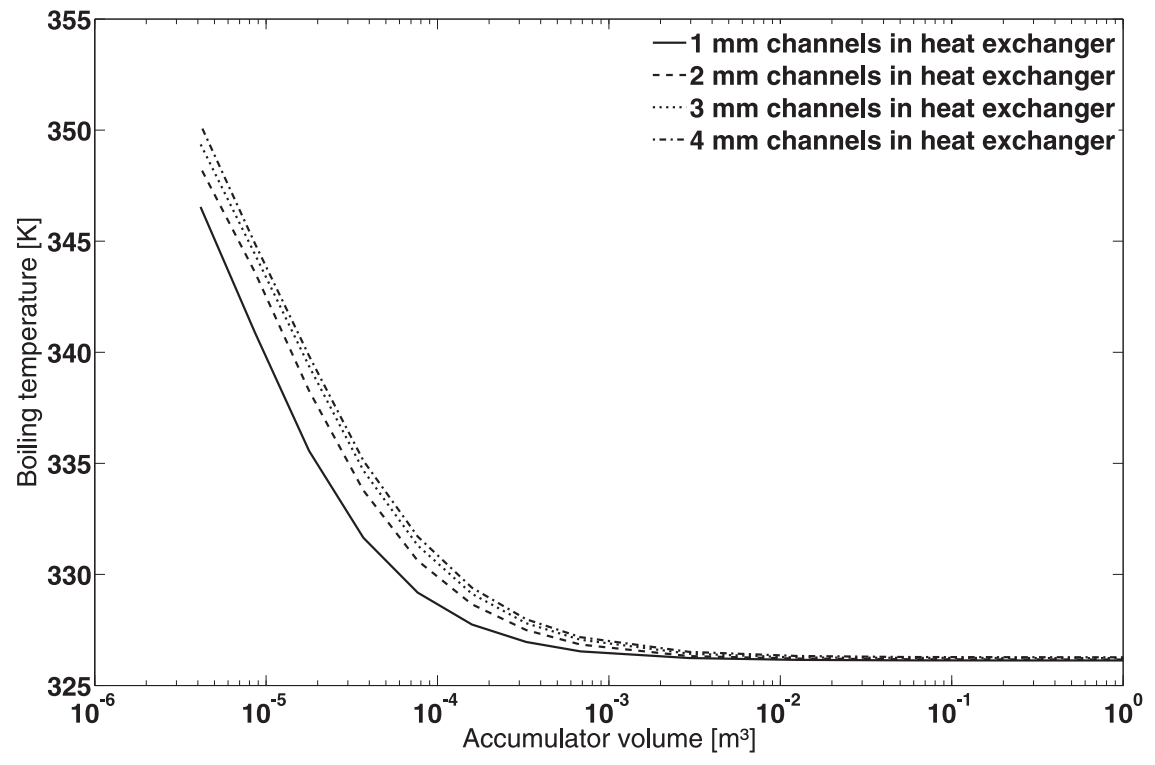

Figure 8: Results from the numerical model for different heat exchanger flow channel widths.

and these volumes are practically independent of the coolant used. However, the individual coolants react differently to pressure changes in the accumulator. This is apparent because the slope of the curves is different for each coolant. From these results it is clear that R134a performs the best and R245fa performs the worse in regard to size effects.

\section{Accumulator design}

In the previous section the magnitude and the influence of system parameters on the size effects are investigated. In this section the design of the accumulator in order to cope with these size effects is elaborated, using the analytic models previously developed.

Starting from an admitted boiling temperature rise $\left(T_{b, 2} / T_{b, 1}\right)$ the resulting accumulator volume can be deduced from the analytical models.

From the analytical model an expression can be derived to calculate the necessary accumulator size for a given system and allowable boiling temperature rise. Neglecting the influence of friction losses, rewriting Eq. (31) and solving for $V_{a c c}$ gives:

$$
V_{a c c}=\left(\alpha V_{t}+\alpha_{a v} V_{h e}\right) \frac{\rho_{l}-\rho_{g}}{\rho_{l}}\left(\frac{1}{1-\left(\frac{p_{a c c}}{\Delta p+p_{a c c}}\right)^{1 / \kappa}}\right)
$$

where $\Delta p$ is the boiling pressure increase associated with an allowable boiling temperature rise of $T_{b, 2} / T_{b, 1}$. This term can be calculated using a material properties program. However, from the previous section the other analytical models for the boiling pressure increase perform similarly 


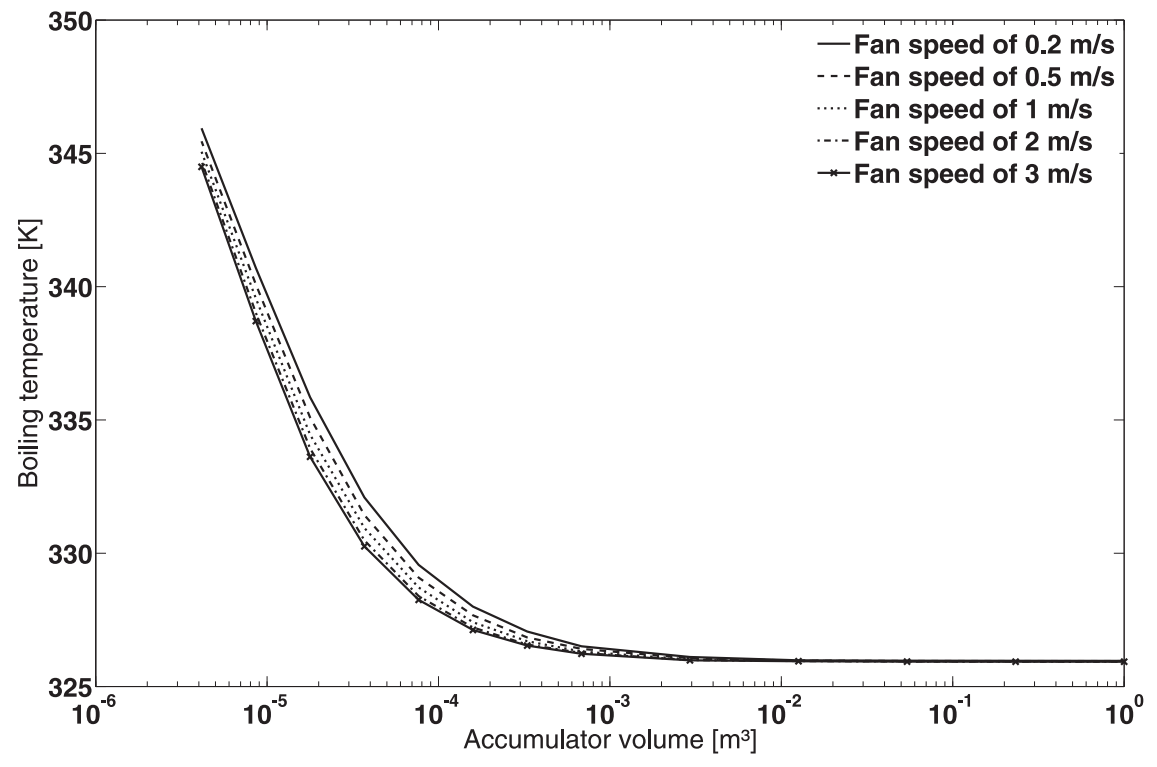

Figure 9: Results from the numerical model for different heat exchanger air speeds.

well. Therefore, either Eq. (16) or Eq. (18) can also be used. Using Eq. (16) the following form is obtained:

$$
V_{a c c}=\left(\alpha V_{t}+\alpha_{a v} V_{h e}\right) \frac{\rho_{l}-\rho_{g}}{\rho_{l}}\left(\frac{1}{1-\left(\frac{p_{a c c}\left(\rho_{l}-\rho_{g}\right)}{\rho_{g} \rho_{l} \ln \frac{I_{b, 2}}{T_{b, 1}} \Delta h+p_{a c c}\left(\rho_{l}-\rho_{g}\right)}\right)^{1 / \kappa}}\right)
$$

Alternatively using Eq. (18) gives:

$$
V_{a c c}=\left(\alpha V_{t}+\alpha_{a v} V_{h e}\right) \frac{\rho_{l}-\rho_{g}}{\rho_{l}}\left(\frac{\exp \left(\frac{\Delta h}{\kappa T_{b, 1} r}\right)}{\exp \left(\frac{\Delta h}{\kappa T_{b, 1} r}\right)-\exp \left(\frac{\Delta h}{\kappa \frac{T_{b, 2}}{T_{b, 1}} T_{b, 1} r}\right)}\right)
$$

These general equations can be used to calculate the necessary accumulator volume for isentropic size effects $(\kappa>1)$ and isothermal size effects $(\kappa=1)$. The only factors of Eq. (32) that are not strictly material properties are $\left(\alpha V_{t}+\alpha_{a v} V_{h e}\right)$., which represents the size of the cooling system, and $\Delta p$, which represents the allowable boiling temperature rise. For a relatively small boiling temperature rise or using mass flow or temperature control, Eq. (32), Eq. (33) or Eq. (34) can be directly used to calculate the necessary accumulator size, using the design values for the vapor quality. However, for a larger temperature rise and no control, the vapor quality and hence the 


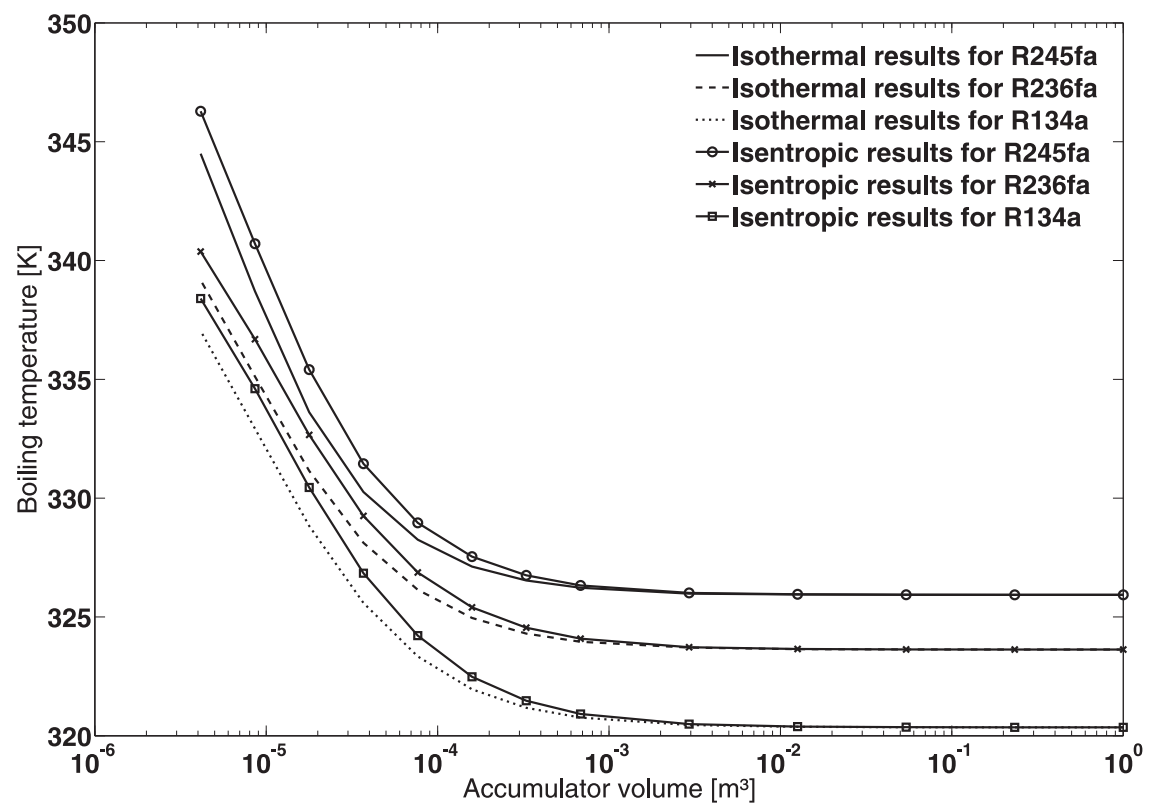

Figure 10: Isothermal and isentropic results from the numerical model for different coolants.

$\left(\alpha V_{t}+\alpha_{a v} V_{h e}\right)$ factor will start to deviate. Eq. (13) can be rewritten as:

$$
x_{e}=\frac{\dot{Q}}{\dot{m} \Delta h}-\frac{c_{p}}{\Delta h}\left(\frac{T_{b, 2}}{T_{b, 1}} T_{b, 1}-T_{i}\right)
$$

Using Eq. (35) to calculate $V_{\text {he }}$, together with a suitable void fraction correlation to calculate $\alpha$ and $\alpha_{a v}$, provides the necessary adjustments to Eq. (32), Eq. (33) and Eq. (34) to correctly calculate the necessary accumulator size.

In Fig. 11 the results for both isothermal and isentropic size effects from the different models for R245fa are plotted. Model A corresponds to Eq. (33), model B to Eq. (34) and model C to Eq. (32). From Fig. 11 it is clear that the different models do not deviate strongly and that the isentropic size effects are again stronger than the isothermal size effects.

In Fig. 12 the results for the isothermal size effects of different refrigerants, using model C are plotted. Similarly to the results of the previous section, R245fa has the worst performance in regard to size effects, followed by R236fa and finally R134a. This means that R245fa needs a larger accumulator for the same allowable boiling temperature rise. Also note that the needed accumulator volume of R134a and R236fa goes to zero at a certain allowable boiling temperature rise. This is because at these high boiling temperatures, the flow does not reach the boiling temperature in the heat sink. Thus, the flow remains liquid, single-phase throughout the system. Eventually the results of R245fa will also go to zero at a higher boiling temperature rise.

In Fig. 13 the results for the isothermal size effects of different control techniques, using model C, for R245fa are plotted. Also similar to the results of the previous section, temperature 


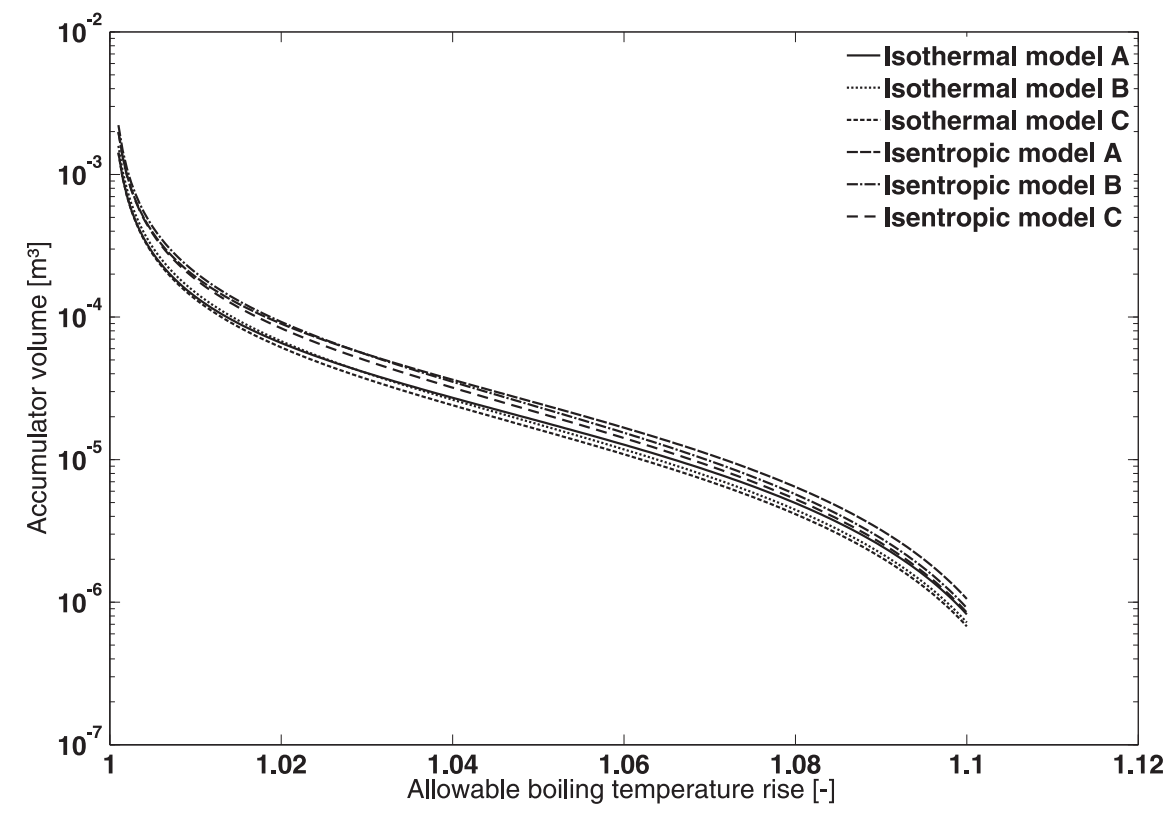

Figure 11: Necessary accumulator volume in function of the allowable boiling temperature rise from the analytic model $\mathrm{A}, \mathrm{B}$ and $\mathrm{C}$.

control has the worst performance in regard to size effects, followed by mass flow control and finally no control. No control performs the best, because the vapor quality and hence the void fraction go to zero when the flow is fully single-phase in the system. With mass flow control and temperature control the flow will always be two-phase in the system, because the exit vapor quality is kept constant by controlling either the mass flow or the inlet temperature. Mass flow control performs better than temperature control, because a decrease in mass flow at higher boiling temperatures means a decrease in two-phase volume in the heat exchanger. With the temperature control both the void fraction and mass flow, and hence the two-phase volume in the heat exchanger will remain constant. From Fig. 13 it seems that both mass flow control and temperature control tend to a certain asymptote at higher boiling temperatures. This is not the case as the flow will approach the critical point of the coolant at a certain point.

In Fig. 14 the results for the isothermal size effects for mass flow and inlet temperature control, using model $\mathrm{C}$ are plotted for different refrigerants at higher boiling temperature rise. From Fig. 14 it is clear that even for mass flow and inlet temperature control, the accumulator volume goes to zero. As mentioned before this is because the coolant reaches the critical point at these higher boiling temperatures.

\section{Conclusion}

A parameter study is performed, using a state of the art dynamic system model, on the size effects of a small cooling system. It is shown that an increase in boiling temperature coupled by 


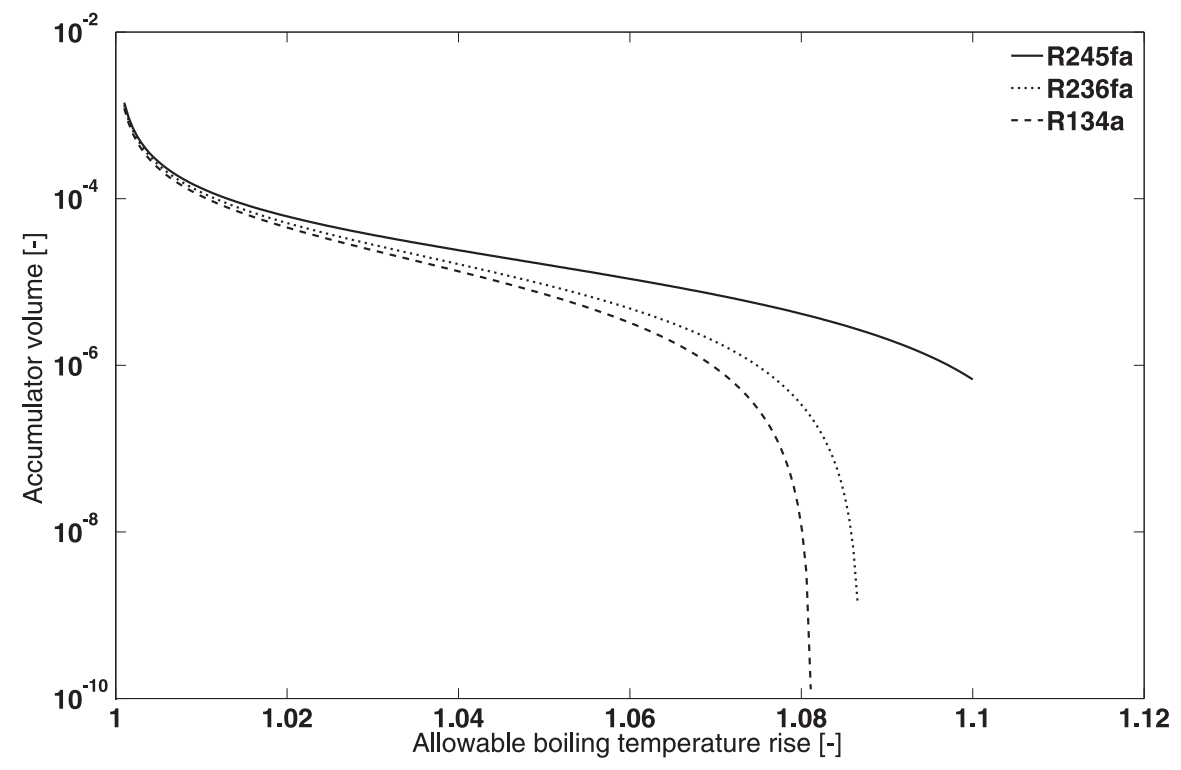

Figure 12: Necessary accumulator volume in function of the allowable boiling temperature rise for different refrigerants using model $\mathrm{C}$.

a decrease in exit vapor quality or mass flow can lead to an unintended high junction temperature. In particular the accumulator and its interaction with the connecting tubing and the heat exchanger play an important role in changing these properties. Additionally, the pressure losses in the system also contribute to changes in the boiling temperature.

An analytical model is developed to predict these size effects in a simple way. It shows good results when compared to the results from a numerical model previously developed. Although it is an iterative model, it converges fast and is simple enough to be used in hand calculations to make first order estimates of the size effects on the cooling system performance.

A close link exists between the connecting tubing volume, heat exchanger two-phase volume and the minimal allowed accumulator size. Smaller connecting tubing allows a smaller accumulator because there is less volumetric change in the loop during transition from single-phase to two-phase. Therefore, it is useful to minimize the tubing length. However, lowering the cross section of the tubing can have a detrimental effect at large accumulator size due to the increase in pressure losses in the system. A similar conclusion can be drawn for the flow channel width of the heat exchanger channels. Finally increasing the air side heat transfer performance (by increasing the air flow for example) of the heat exchanger will also decrease the two-phase volume in the heat exchanger and therefore improve the size effects.

Additionally, a design equation is developed from the analytical model to calculate the needed accumulator size for a given allowable boiling temperature rise. Using this design equation it is shown that already substantial accumulator sizes are needed at low boiling temperature rises. The performance of three different refrigerants (R134a, R236fa, R245fa) in regard to the size effects is investigated. It is shown that for similar flow conditions, R134a performs the best and R245fa 


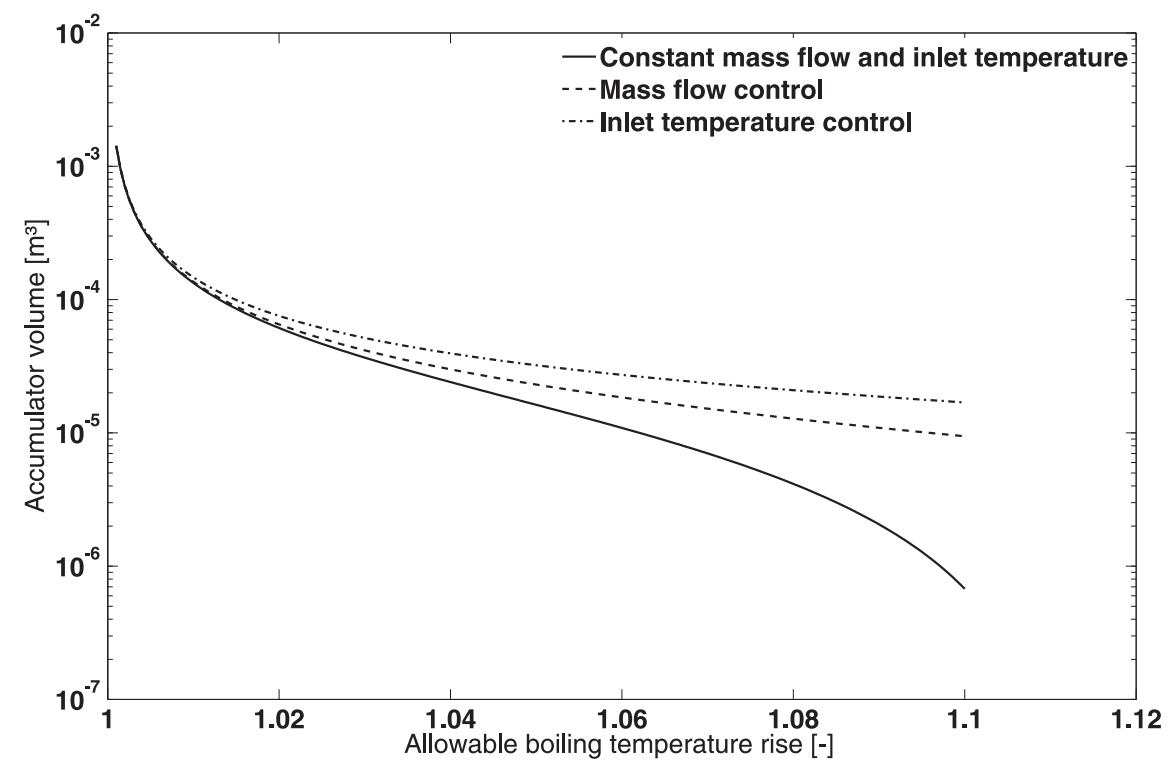

Figure 13: Necessary accumulator volume in function of the allowable boiling temperature rise for different control techniques using model $\mathrm{C}$.

performs the worst. Finally three different control techniques (no control, mass flow control and inlet temperature control) are also compared. Of these, temperature control has the worst size effects, followed by mass flow control and finally no control.

\section{Acknowledgements}

This work is sponsored by the IWT, The Institute for the Promotion of Innovation by Science and Technology in Flanders, Belgium, project SBO 60830, HyperCool-IT.

\section{Nomenclature}

\section{Variables}

$A$ cross sectional area $\left[\mathrm{m}^{2}\right]$

$C_{c}$ contraction coefficient [-]

$c_{p}$ heat capacity at constant pressure $[J /(\mathrm{kgK})]$

$c_{v}$ heat capacity at constant volume $[\mathrm{J} /(\mathrm{kgK})]$

$d$ diameter $[m]$

$D_{h}$ hydraulic diameter $[m]$ 


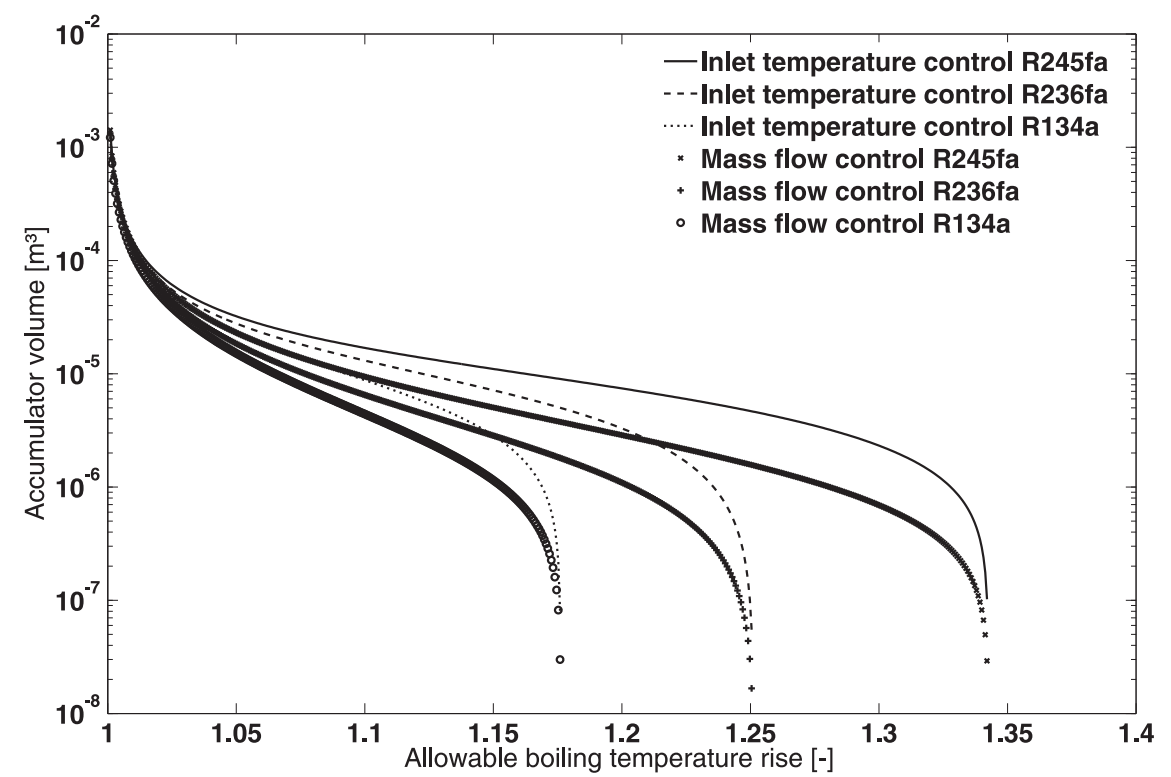

Figure 14: Necessary accumulator volume in function of the allowable boiling temperature rise for mass flow and inlet temperature control at high temperature rises, using model C.

$F$ frictional and local pressure losses $\left[\mathrm{N} / \mathrm{m}^{3}\right]$

$f$ Darcy friction factor [-]

$F i$ fin

$G$ mixture mass flux $\left[\mathrm{kg} /\left(\mathrm{m}^{2} \mathrm{~s}\right)\right]$

$g$ gravitational acceleration $\left[\mathrm{m} / \mathrm{s}^{2}\right]$

$h$ enthalpy $[\mathrm{J} / \mathrm{kg}]$

$h$ mixed-cup enthalpy $[\mathrm{J} / \mathrm{kg}]$

$h^{\star}$ mixture specific enthalpy $[\mathrm{J} / \mathrm{kg}]$

$K$ local pressure loss factor [-]

$k$ thermal conductivity $[W /(m K)]$

$L$ length $[m]$

$L_{h p}$ length tubing between heat exchanger and pump [m]

Lo louver 
$\dot{m}$ mass flow $[k s / s]$

$m$ mass $[k g]$

$n$ number of channels [-]

$P$ pressure $[\mathrm{Pa}]$

$P_{m}$ perimeter of flow channel $[\mathrm{m}]$

$\dot{Q}$ heat flow $[W]$

$q$ heat flux $\left[\mathrm{W} / \mathrm{m}^{2}\right]$

$R$ thermal resistance $[K / W]$

$r$ specific gas constant $[\mathrm{J} /(\mathrm{kgK})]$

Re Reynolds number [-]

$s$ streamwise coordinate $[\mathrm{m}]$

$t$ time $[s]$

$T_{c}$ mixture temperature $[K]$

$t_{h}$ thickness silicon substrate $[m]$

$U$ global heat transfer coefficient $\left[W /\left(m^{2} K\right)\right]$

$u$ velocity $[\mathrm{m} / \mathrm{s}]$

$V$ volume $\left[m^{3}\right]$

$W$ width $[m]$

$w_{w}$ microchannel wall width [m]

$x$ vapor quality [-]

\section{Greek Symbols}

$\alpha$ void fraction [-]

$\kappa$ ratio of specific heats [-]

$\mu$ dynamic viscosity [Pas]

$v$ specific volume $\left[\mathrm{m}^{3} / \mathrm{kg}\right]$

$\rho$ mixture density $\left[\mathrm{kg} / \mathrm{m}^{3}\right]$

$\rho^{\prime}$ apparent momentum density $\left[\mathrm{kg} / \mathrm{m}^{3}\right]$

$\rho^{\prime \prime}$ apparent energy density $\left[\mathrm{kg} / \mathrm{m}^{3}\right]$

$\sigma$ flow area contraction [-] 


\section{$\theta$ inclination degree [-]}

\section{Subscripts}

acc accumulator

$a v$ average

$b$ boiling

ch microchannel

$e$ exit

$g$ vapor

he heat exchanger

env environment

$i$ entrance

ig inert gas

$l$ liquid

$t$ tubing

\section{References}

[1] D. Tuckerman, R. Pease, High-performance heat sinking for vlsi, IEEE Electron Device Letters 2 (1981) 126-129.

[2] C. Sobhan, S. Garimella, A comparative analysis of studies on heat transfer and fluid flow in microchannels, Microscale Thermophysical Engineering 5 (2001) 293-311.

[3] G. Morini, Single-phase convective heat transfer in microchannels: a review of experimental results, International Journal of Thermal Sciences 43 (2004) 631-651.

[4] G. Morini, Scaling effects for liquid flows in microchannels, Heat Transfer Engineering 27 (2006) 64-73.

[5] D. Liu, S. Garimella, Investigation of liquid flow in microchannels, Journal of Thermophysics and Heat Transfer 18 (2004) 65-72.

[6] J. Thome, State-of-the-art overview of boiling and two-phase flows in microchannels, Heat Transfer Engineering 27 (2006) 4-19.

[7] S. Bertsch, E. Groll, S. Garimella, Review and comparative analysis of studies on saturated flow boiling in small channels, Nanoscale and Microscale Thermophysical Engineering 12 (2008) 187-227.

[8] W. Qu, I. Mudawar, Measurement and prediction of pressure drop in two-phase micro-channel heat sinks, International Journal of Heat and Mass Transfer 46 (2003) 2737-2753.

[9] W. Qu, I. Mudawar, Flow boiling heat transfer in two-phase micro-channel heat sinks - i. experimental investigation and assessment of correlation methods. International Journal of Heat and Mass Transfer 46 (2003) 2755-2771.

[10] T. Harirchian, S. Garimella, Microchannel size effects on local flow boiling heat transfer to a dielectric fluid, International Journal of Heat and Mass Transfer 51 (2008) 3724-3735.

[11] W. Qu, I. Mudawar, Flow boiling heat transfer in two-phase micro-channel heat sinks - ii. annular two-phase flow model, International Journal of Heat and Mass Transfer 46 (2003) 2773-2784.

[12] J. Thome, V. Dupont, A. Jacobi, Heat transfer model for evaporation in microchannels. part i: presentation of the model, International Journal of Heat and Mass Transfer 47 (2004) 3375-3385.

[13] P. Lee, S. Garimella, Saturated flow boiling heat transfer and pressure drop in silicon microchannels arrays, International Journal of Heat and Mass Transfer 51 (2008) 789-806.

[14] S. Bertsch, E. Groll, S. Garimella, A composite heat transfer correlation for saturated flow boiling in small channels, International Journal of Heat and Mass Transfer 52 (2009) 2110-2118. 
[15] J. Marcinichen, J. Thome, B. Michel, Cooling of microprocessors with micro-evaporation: A novel two-phase cooling cycle, International Journal of Refrigeration 33 (2010) 1264-1276.

[16] T. Zhang, J. Wen, A. Julius, Y. Peles, M. Jensen, Stability analysis and maldistribution control of two-phase flow in parallel evaporating channels, International Journal of Heat and Mass Transfer 54 (2011) 5298-5305.

[17] G. Wedekind, B. Bhatt, B. Beck, A system mean void fraction model for predicting various transient phenomena associated with two-phase evaporating and condensing flows, International Journal of Multiphase flow 4 (1978) $97-114$.

[18] M. Willatzen, N. Pettit, L. Ploung-Sorensen, A general dynamic simulation model for evaporators and condensers in refrigeration. part i-ii, International Journal of refrigeration 21 (1998) 398-414.

[19] T. Saenen, T. Delesie, T. Persoons, M. Baelmans, Towards a dynamic system model for a two-phase cooling loop using microchannels, in: Proceedings of the 15th International Workshop on Thermal Investigations of ICs and Systems (THERMINIC), Leuven (Belgium).

[20] T. Saenen, M. Baelmans, Modeling size effects of a portable two-phase electronics cooling loop with different refrigerants, in: Proceedings of the International Heat Transfer Conference, IHTC 14, ASME, Washington DC (USA).

[21] T. Saenen, M. Baelmans, Numerical model of a two-phase microchannel heat sink electronics cooling system, International Journal of Thermal Sciences 59 (2012) 214-223.

[22] S. Ghiaasiaan, Two-Phase Flow, Boiling, and Condensation in Conventional and Miniature Systems, Cambridge University Press, New York, 2008.

[23] S. Patankar, Numerical Heat Transfer and Fluid Flow, McGraw-Hill, New York, 1980.

[24] A. Premoli, D. Francesco, A. Prina, A dimensionless correlation for determining the density of two-phase mixtures, Lo Termotecnica 25 (1971) 17-26.

[25] W. Zhang, T. Hibiki, K. Mishima, Correlations of two-phase frictional pressure drop and void fraction in minichannel, International Journal of Heat and Mass Transfer 53 (2010) 453-465.

[26] F. White, Fluid Mechanics, McGraw-Hill, New York, 5 edition, 2003.

[27] R. Lockhart, R. Martinelli, Proposed correlation of data for isothermal two-phase, two-component flow in pipes, Chemical Engineering Progress 45 (1949) 39-48.

[28] T. Yilmaz, General equations for pressure drop for laminar flow in ducts of arbitrary cross sections, Journal of Energy Resources Technology 112 (1990) 220-223.

[29] J. Lee, I. Mudawar, Two-phase flow in high-heat-flux micro-channel heat sink for refrigeration cooling applications: Part i - pressure drop characteristics, International Journal of Heat and Mass Transfer 48 (2005) 928-940.

[30] T. Stevens, F. Rogiers, S. Delport, P. Vleugels, J. Peirs, M. Baelmans, Collector pressure losses in micro heat exchangers, Thermal Issues in Emerging Technologies 1 (2007) 11-17.

[31] G. Celata, M. Cumo, S. McPhail, G. Zummo, Characterization of fluid dynamic behaviour and channel wall effects in microtube, International Journal of Heat and Fluid Flow 27 (2006) 135-143.

[32] T. Saenen, T. Persoons, J. Peirs, M. Baelmans, Frictional and collector pressure losses in rectangular microchannels, in: Proceedings of 25th Annual IEEE Semiconductor Thermal Measurement and Management Symposium, IEEE, pp. 121-127.

[33] W. Kays, Loss coefficients for abrupt changes in flow cross section with low reynolds number flow in single and multiple tube systems, Transactions of the ASME (1950) 1067-1074.

[34] F. Abdelall, G. Hahn, S. Ghiaasiaan, S. Abdel-Khalik, S. Jeter, M. Yoda, D. Sadowski, Pressure drop caused by abrupt flow area changes in small channels, Experimental Thermal and Fluid Science 29 (2005) 425-434.

[35] G. Geiger, Sudden Contraction Losses in Single and Two-Phase Flow, Ph.D. thesis, University of Pittsburgh, 1964.

[36] D. Liu, P. Lee, S. Garimella, Prediction of the onset of nucleate boiling in microchannel flow, International Journal of Heat and Mass Transfer 48 (2005) 5134-5149.

[37] P. Saha, N. Zuber, Point of net vapor generation and vapor void fraction in subcooled boiling, Proc. Int. Heat Transfer Conf. 4 (1974) 175-179.

[38] Y. Muzychka, M. Yovanovich, Laminar forced convection heat transfer in the combined entry region of non-circular ducts, Journal of Heat Transfer-Transactions of the ASME 126 (2004) 54-61.

[39] V. Gnielinski, New equations for heat and mass transfer in turbulent pipe and channel flow, International Chemical Engineering 16 (1976) 359-368.

[40] M. Shah, A general correlation for heat transfer during film condensation inside pipes, International Journal of Heat and Mass Transfer 22 (1979) 547-556.

[41] M. Kim, C. W. Bullard, Air-side thermal hydraulic performance of multi-louvered fin aluminum heat exchangers, International Journal of Refrigeration 25 (2002) 390-400.

[42] E. Lemmon, M. Huber, M. McLinden, NIST Standard Reference Database 23: Reference Fluid Thermodynamic and Transport Properties-REFPROP, Version 8.0, National Institute of Standards and Technology, Standard Reference Data Program, Gaithersburg, 2007.

[43] S. Zivi, Estimation of steady state steam void-fraction by means of principle of minimum entropy production, 
ASME Trans. Series C 86 (1964) 237-252. 